\title{
Clinical reasoning in osteopathy - More than just principles?
}

\author{
Oliver P. Thomson, Nicola J. Petty, Ann P. Moore
}

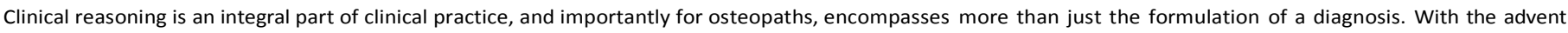

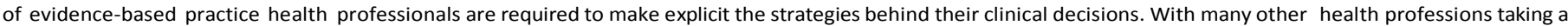

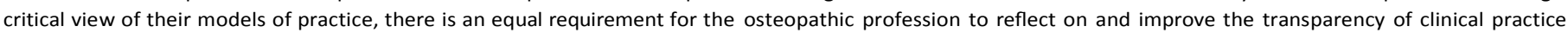

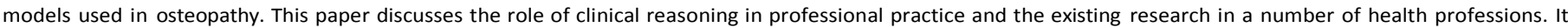

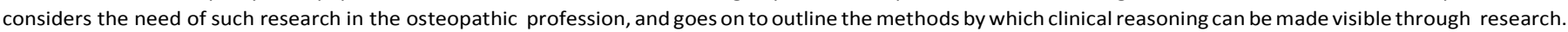

\section{Introduction}

With the number of osteopaths in the UK exceeding over $4000{ }^{1}$ osteopaths are increasingly being seen as core deliverers of neuromusculoskeletal care, particularly in the management of people with non-specific low back pain. ${ }^{2}$ Osteopaths in the UK are auton-

omous practitioners who require a wide-ranging knowledge and skill base, reflected by the range of musculoskeletal and non- musculoskeletal conditions which they encounter. ${ }^{3}$

The advent of the Department of Health Quality Agenda in $1998^{4}$ was one of the several forces to set about a shift to evidence-based

practice (EBP). EBP has placed pressure on health professions to assure the public of rigorous, scientific practice. Part of this accountability is to make explicit and demystify aspects of clinical practice for the purposes of scrutiny, critique and further investi- gation, by those within the profession as well as consumers, external stakeholders and other health professions. One aspect of clinical practice which remains poorly understood is the processes by which practitioners make diagnostic, therapeutic and manage- ment decisions with their patients, termed clinical reasoning. Once it is made more explicit through research, clinical reasoning in oste- opathic practice can begin to be defined, developed and explored. Explicating osteopathic clinical reasoning is therefore necessary to provide the profession, educators and external stakeholders with a greater understanding of osteopathic clinical practice.

\section{Defining clinical reasoning}

The term 'clinical reasoning' has different meanings to different people, and a range of terms exist in the literature to describe it. This variation in terminology represents a historical change in the focus of health professions, and a movement toward the biopsychosocial model of care. ${ }^{5,6,7}$ At present there is little consensus of a universal definition, rather, the term appears to be largely conceptualised according to the professions' values. One of the earliest descriptions and one that many osteopaths may be familiar with is the term clinical problem-solving. Clinical problem- solving has its origin in the medical profession and was used to describe the cognitive process practitioners employed to 'solve'

(the often unsolvable!) patients' problems. ${ }^{8}$ As a term 'clinical problem-solving' fails to describe the complex process of clinical reasoning which occurs in the osteopathic (and other health professionals) patient encounter for two main reasons: 1 ) it somewhat narrowly denotes that the clinicians' main objective is to find and solve problems, by formulating diagnoses and differ- ential diagnoses, with little regard to the treatment and manage- ment aspects of the patient; 2) Considering the patient as a 'problem' or series of 'problems' does little to empower the patient, nor does it add to the notion of including the patient in the

decision-making process. ${ }^{9}$ The concept of problem-solving emerged during a period when there was great emphasis on the 
disease, rather than the patient with the disease. For that reason the concept may be too centered on diagnosis formulation, in order for it to be seamlessly transferred to allied health profes- sions, including osteopathy.

Research into health professions over the past 25 years has vastly expanded upon the early descriptions of clinical reasoning, in line with contemporary models of health and disability. ${ }^{5}$ This research has shown clinical reasoning to be a dynamic process

which occurs throughout the patient encounter, and moves beyond the point of diagnosis formation. ${ }^{10,11,12,13}$ Clinical reasoning is now viewed as "a process in which the clinician, interacting with

significant others (client, caregivers, healthcare team members), structures meaning, goals and health management strategies based on clinical data, client choices, and professional judgement and knowledge $^{14}$ (P. 11). This much broader description has elements which are particularly suited for its use in the osteopathic context of healthcare: Firstly, it incorporates the patient 'voice' so that they may collaborate with the practitioner (and other health profes- sionals) to achieve improved health status; and secondly, it recognises that clinical reasoning is a dynamic process which is informed by different sources and types of knowledge.

Clinical reasoning has been described as 'a bridge between practice and knowledge ${ }^{15}$ (P. 11). Without such a bridge developed from research, the credibility of osteopathy and its claim as

a 'profession' may be challenged. Research into clinical reasoning in osteopathy will contribute to a platform for future work exploring the nature of osteopathic expertise, and the methods by which novice osteopathic practitioners may attain such expertise, enabling them to safely and effectively treat their patients.

\section{Clinical reasoning in other health professions}

Clinical reasoning involves complex processes (also termed strategies) through which clinicians make diagnostic, treatment and management decisions about patients and crucially with their patients, and is regarded as the foundation of professional clinical practice. ${ }^{16}$ Importantly, clinical reasoning encompasses more than

just the process of reaching a diagnosis, which while pivotal, is just part of a range of clinical reasoning strategies at a clinicians' disposal. ${ }^{17,18,19,20,21}$ Research in the health sciences has identified the clinical reasoning strategies used in different health professions.

While all health professions tend to share common core compo- nents (such as diagnostic, procedural and narrative reasoning), the approach each profession takes to clinical reasoning varies, and a number of different clinical reasoning strategies have been iden-

tified though research or proposed theoretically: in nursing; ${ }^{13,22}$ in occupational therapy; ${ }^{17,18,19}$ and in physiotherapy. ${ }^{10,20,21,23}$ Table 1 illustrates the clinical reasoning strategies identified in a range of health professions.

Researchers in occupational therapy have identified that occupational therapists tend to employ three major clinical reasoning strategies during a patient encounter; procedural, interactive and conditional reasoning strategies. Occupational therapists are often described as having a "three track mind"19 ${ }^{19}$ when using these three strategies either alone or in unison. In the nursing profession, the research literature emphasises ethical reasoning, which involves makingdecisionsorjudgementsaboutmoralorethicaldilemmas. ${ }^{35}$

Researchers began investigating the clinical reasoning used by physiotherapists in the mid 1980's. Initially proposed by Jones, ${ }^{6}$ and later developed by Edwards, ${ }^{9}$ a 'collaborative' clinical reasoning process was suggested as a model of clinical reasoning for use in physiotherapy. The model depicts the cyclical process of hypothesis

generation, testing and subsequent modification, with a strong emphasis on both the patients' and clinicians' thoughts during the clinical reasoning process. $^{39,40}$ One particularly attractive aspect of this model was the incorporation of metacognition. Metacognition or "thinking about your thinking and the factors that limit it", describes the process by which practitioners monitor their thinking and actively reflect on aspects of their practice such as data collection during clinical examination, clinical reasoning and subsequent treatment procedures. Metacognition involves thinking

at a higher level than cognition, and is well recognised as an attribute of clinical expertise in physical therapy. ${ }^{12,42,43,44,45}$ Metacognition is believed to be the link that allows practitioners to learn from

experiences in clinical practice. Experimental evidence supports the view that high metacognitive skills are associated with enhanced performances in problem-solving ${ }^{46}$ and the importance of incor-

porating metacognition into clinical reasoning education has been recognised. 47

Further research by Edwards et al. ${ }^{20}$ identified the clinical reasoning strategies used by physiotherapists during a patient

encounter. The strategies appeared to be driven by cues from the patientetherapist interaction, and could be employed individually but were often employed in combination with each other at any given time. ${ }^{20}$ For example, using posture re-education tech-

niques (strategy: teaching as reasoning) to provide information on symptom reproduction (strategy: diagnostic reasoning). Emphasis- ing the distinctiveness of each strategy, Edwards ${ }^{20}$ asserts that "each

clinical reasoning strategy requires an orientation of thinking and action, which is not subsumed by the other" (P. 323). The strategies identified by Edwards $^{20}$ (Table 1) correspond with reasoning strat- egies identified in existing physiotherapy research and previously in other health professions; diagnostic reasoning (medicine), ${ }^{8}$ proce- dural, ${ }^{19}$ interactive, and predictive (or conditional) reasoning ${ }^{19}$

(occupational therapy), collaborative reasoning ${ }^{30}$ and teaching as reasoning ${ }^{31}$ (physiotherapy), and ethical reasoning ${ }^{36}$ (nursing).

\section{Clinical reasoning in osteopathy e a need for research}

Many-a-clinic tutor (and osteopathic student) will be familiar with the situation whereby the student hypothetically-deductively 'does the rounds' of possible diagnoses.. "disc, facet joint.. sacroiliac joint etc". As clinicians, we are all familiar with formu- lating a diagnostic hypothesis, then confirming or refuting it by further investigation, be it pain provocation, passive joint motion, neurological or orthopaedic tests. Experienced practitioners may travel through the process of diagnosis formulation swiftly, effi- ciently and almost unconsciously, this is termed pattern recogni-

tion. ${ }^{48}$ Hypothetico-deductive reasoning and pattern recognition,

are well recognised diagnostic reasoning strategies used by a number of health professions, including medicine $8,48,49$ physiotherapy ${ }^{20,23,26}$ and osteopathy. ${ }^{50,51,52,53}$ Hypothetico-deductive reasoning and pattern recognition help to describe how, as practi- tioners we arrive at a diagnosis, which is a fundamental 'step' in

clinical practice. However, little is known about the clinical reasoning strategies that occur during the ongoing treatment and management aspects of the osteopathic patient encounter. Return- ing to the description of clinical reasoning offered earlier, how does an osteopath navigate a course from the formulation of a diagnosis, to the treatment (structuring of treatment plans, setting of goals and implementation of health management strategies) of their patient? It is likely to be more than just the application of osteopathic principles.

While osteopaths throughout the years have relied upon osteopathic principles to guide practice, without research available to describe the actual nature of clinical reasoning used in osteopathy this remains an assumption. While the works of the early osteo- pathic pioneers have shaped the osteopathic profession, it is not satisfactory to continue to rely on such a limited body of work from a small number of individuals. By doing so we cannot claim to be 
Table 1

Clinical reasoning strategies identified in a range of health professions.

\begin{tabular}{|c|c|c|c|c|c|}
\hline $\begin{array}{l}\text { Clinical } \\
\text { reasoning } \\
\text { strategy }\end{array}$ & Definition $^{20}$ & Example & $\begin{array}{l}\text { Occupational } \\
\text { Therapy }\end{array}$ & Nursing & Physiotherapy \\
\hline $\begin{array}{l}\text { Diagnostic } \\
\text { reasoning }\end{array}$ & $\begin{array}{l}\text { The formation of a diagnosis related to physical disability and } \\
\text { impairment with consideration of associated pain mechanisms, tissue } \\
\text { pathology, and the broad scope of potential } \\
\text { contributingfactors. }\end{array}$ & $\begin{array}{l}\text { Include diagnosis formulation by hypothetico-deductive } \\
\text { reasoning and pattern recognition in order to reveal the } \\
\text { underlying pain mechanisms and tissues causing symptoms. } \\
\text { Imagining the 'life story' of how a patient copes at home }\end{array}$ & Rogers and $\mathrm{Holm}^{24}$ & Tanner et al. ${ }^{25}$ & $\begin{array}{l}\text { Doody and } \\
\text { McAteer } \\
\text { Edwards et al }^{20} \\
\text { Payton }^{23} \text { Edwards }^{20}\end{array}$ \\
\hline $\begin{array}{l}\text { Narrative } \\
\quad \text { reasoning }\end{array}$ & $\begin{array}{l}\text { Involves the apprehension and understanding of patients' "stories," } \\
\text { illness experiences, meaning perspectives, contexts, beliefs, } \\
\text { and cultures. }\end{array}$ & $\begin{array}{l}\text { following a stroke or the impact that knee arthrosis has } \\
\text { on the work of a taxi driver. }\end{array}$ & $\begin{array}{l}\text { Mattingly and } \\
\text { Fleming }^{18}\end{array}$ & Benner et al. $^{22}$ & $\begin{array}{l}\text { et al. } 20 \\
\text { Edwards }^{10}\end{array}$ \\
\hline $\begin{array}{l}\text { Procedural } \\
\text { reasoning }\end{array}$ & $\begin{array}{l}\text { The decision-making behind the determination and carrying out of } \\
\text { treatment and examination procedures. }\end{array}$ & $\begin{array}{l}\text { The use palpation procedures to inform a joint } \\
\text { manipulation or muscle-energy technique. }\end{array}$ & $\begin{array}{l}\text { Fleming }^{19} \\
\text { Unsworth }^{27}\end{array}$ & Benner $^{28}$ & Edwards et al. ${ }^{20}$ \\
\hline $\begin{array}{l}\text { Interactive } \\
\quad \text { reasoning }\end{array}$ & $\begin{array}{l}\text { The purposeful establishment and ongoing management of therapist patient } \\
\text { rapport. }\end{array}$ & $\begin{array}{l}\text { Engaging in conversation with a patient periodically to } \\
\text { continually assess the effects of a joint mobilisation } \\
\text { technique. }\end{array}$ & $\begin{array}{l}\text { Fleming }^{19} \\
\text { Unsworth }\end{array}$ & & Edwards et al. ${ }^{20}$ \\
\hline $\begin{array}{r}\text { Collaborative } \\
\text { reasoning }\end{array}$ & $\begin{array}{l}\text { The nurturing of a consensual approach toward the interpretation of } \\
\text { examination findings, the setting of goals and priorities, and the } \\
\text { implementation and progression of intervention. }\end{array}$ & $\begin{array}{l}\text { The collaboration during a muscle-energy technique } \\
\text { or the practitioner-patient cooperation established } \\
\text { during goal setting for a rehabilitative exercise } \\
\text { programme. }\end{array}$ & $\begin{array}{l}\text { Mattingly and } \\
\text { Fleming }\end{array}$ & & $\begin{array}{l}\text { Edwards et al. }{ }^{20,21} \\
\text { Jensen et al. }{ }^{30}\end{array}$ \\
\hline $\begin{array}{l}\text { Reasoning about } \\
\text { teaching }\end{array}$ & $\begin{array}{l}\text { Involves thinking directed to the content, method, and amount of } \\
\text { teaching in clinical practice, which is then assessed as to whether } \\
\text { it has been effectively understood. }\end{array}$ & $\begin{array}{l}\text { The information gained from the performance of a } \\
\text { rehabilitative exercise to further inform the diagnosis, } \\
\text { treatment approach or prognosis. }\end{array}$ & & & $\begin{array}{l}\text { Edwards et al. }{ }^{20} \\
\text { Sluijis }\end{array}$ \\
\hline $\begin{array}{l}\text { Predictive } \\
\text { reasoning }\end{array}$ & $\begin{array}{l}\text { The active envisioning of future scenarios with patients, including } \\
\text { the exploration of their choices and the implications of those choices. }\end{array}$ & $\begin{array}{l}\text { Predicting the clinical course and outcome of a patient } \\
\text { with acute neck pain (response to current and future } \\
\text { treatment approaches, possible referral to specialist). The use }\end{array}$ & $\begin{array}{l}\text { Fleming }^{19} \\
\text { (termed conditional } \\
\text { reasoning) }\end{array}$ & $\begin{array}{l}\text { Fisher and } \\
\text { Fonteyn }\end{array}$ & Edwards et al. ${ }^{20}$ \\
\hline $\begin{array}{l}\text { Ethical } \\
\quad \text { reasoning }\end{array}$ & $\begin{array}{l}\text { Includes the apprehension of ethical and practical dilemmas that } \\
\text { impinge on both the conduct of intervention and its desired goals, and the } \\
\text { resultant action toward their resolution. }\end{array}$ & $\begin{array}{l}\text { of ethics found in professional codes of practice } \\
\text { or ethics from past life and clinical experiences (e.g. } \\
\text { informed consent, confidentiality issues). }\end{array}$ & $\begin{array}{l}\text { Schell and Cervero } \\
\text { Unsworth }^{33} \\
\text { (termed pragmatic } \\
\text { reasoning) }\end{array}$ & $\begin{array}{l}\text { Goethals et al }{ }^{35} \\
\text { Gordon et al. }{ }^{36}\end{array}$ & $\begin{array}{l}\text { Beeston and } \\
\text { Simons }{ }^{37} \\
\text { Edwards et al. }^{20} \\
\text { Edwards and } \\
\text { Delany }\end{array}$ \\
\hline
\end{tabular}


a progressive and reflective profession. By definition, a profession is required to possess a discrete body of knowledge to be used within its teaching and practice, which is vital for academic credibility and

legitimacy. ${ }^{54}$ An understanding of a health professionals' clinical

reasoning forms part of this body of knowledge, illuminating what

they do, how they do it and why they do it. ${ }^{54}$

Not possessing an understanding of clinical reasoning has not only educational, professional and political ramifications, but also impacts practicing osteopaths, at the 'coal face' of the profession. Osteopaths need to be able to explain the reasons behind their treatment choices to their patients, and clinical reasoning provides the conduit for this to occur effectively. Moreover, clinical reasoning is a complex process, and osteopaths have to treat and manage patients with complex problems. Therefore, sound clinical reasoning is required for osteopaths to effectively manage these patients. Understanding the complexity of osteopathic clinical reasoning will enable osteopaths to reason more effectively.

In order to provide high quality services to members of the public, osteopaths need evidence to support all aspects of their practice. Today as the demands of an overstretched healthcare system increases, theclinicalreasoning ofallhealthcareprofessions

must be placed within the context evidence-based practice(EBP). ${ }^{55}$

In recognising that the ultimate goal of EBP is to inform clinical decisions, EBP should perhaps, and importantly for this discussion, be more suitably called 'evidence-informed decision-making'. ${ }^{56}$

The application of these research findings should not occur in isolation, but rather in the context of patient-centred clinical reasoning. Clinical reasoning research would provide the necessary framework by which osteopaths can integrate this research with different forms of knowledge, in a particular way for a particular

patient, constituting what is known as professional artistry. ${ }^{57}$

In the UK there is no 'core' curriculum in place in osteopathic education, but there are 'Standards of Proficiency' for osteopathic education and practice, set by the General Osteopathic Council. ${ }^{58}$ Interestingly, this document is explicit in stating clinical reasoning

as an 'area of capability' for the 'safe and competent practice of osteopathy' (P. 4). Without a body of research to explain what clinical reasoning in the context of osteopathy 'looks like', means this area of competence is largely left up to the interpretation of osteopaths and educators alike. Clinical reasoning has been widely acknowledged as a vital part in health profession education and is the nucleus of professional practice. Without knowledge of clinical reasoning processes in osteopathy the profession will have difficulty in char- acterising its professional approach, thereby placing an obstacle for inter-professional learning and understanding. Research is necessary to provide an understanding of the nature and scope of clinical reasoning used by osteopaths, giving an important and much needed insight into aspects of osteopathic practice which have not been investigated to date. The ability of the osteopathic profession to articulate its clinical reasoning will facilitate the understanding of facets of clinical practice, such as professional artistry, expertise and

how practitioners learn and develop these skills in clinical practice. ${ }^{59}$

Identifying the nature of the clinical reasoning strategies employed in osteopathic practice, is an important part of address- ing issues regarding professional scope and values, and enabling questions such "How do clinical reasoning processes employed by osteopaths compare and contrast with other health professions"? "How do novice and experienced osteopaths clinically reason"? to be answered. Whilst osteopathic patient approaches vary between practitioners, it is often claimed that osteopathic practice is

underpinned by the osteopathic principles derived through the seminal work of A.T. Still ${ }^{60}$ and other osteopathic scholars. ${ }^{61,62}$ Yet little is known about how these principles might drive osteopathic decision-making in practice. What role do the osteopathic princi-

ples play in clinical reasoning, if any?
To give an example, an osteopath may bear in mind the principle 'the rule of the artery is supreme, ${ }^{, 63}$ during the treatment of a patient with an entrapment neuropathy at the wrist. They may mobilise and manipulate the soft tissues and joints of the thoracic outlet and

the cervicothoracic spine with the aim to enhance the fluid dynamics of the upper extremity. They may also offer postural, exercise and lifestyle advice for the longer term management of the patient. However, the 'rule of the artery' (nor a combination of any of the other osteopathic principles) is unable to fully explain the subtle and complex interplay of different clinical reasoning processes used in the treatment and management of a patient such as this. This is where clinical reasoning research can help bridge the gap between osteopathic principles and practice. Research would help explain some of the hidden components contained within the 'black box' of the osteopath-patient encounter, making it available for current practitioners to learn from, for educators to teach from and for researchers to further expand upon.

\section{How to make the invisible visible? e clinical reasoning research}

Researchers across the health professions have been attempting to understand the process of clinical reasoning for the past three decades, with the majority of the research focusing primarily on the process practitioners use to arrive at a diagnosis. Research into clinical reasoning has used both qualitative and quantitative methodological approaches to data gathering and analysis. The pioneers in clinical reasoning research operated predominately in the empirico-analytical paradigm, using both quantitative and

qualitative data. ${ }^{64}$ Research into clinical reasoning is faced with numerous difficulties; with the main factor that clinical reasoning is a cognitive process and therefore resides in the mind of the clini- cian, which is largely hidden from observers. With this difficulty in mind, a range of research methods, operating in different research paradigms have been used to investigate the different aspects of clinical reasoning. ${ }^{64}$ Quantitative approaches may be better suited to limit, test or compare aspects of clinical reasoning ${ }^{64}$ (for example 'do experts or novices generate more differential diagnoses?'), while qualitative methods will illuminate factors which can help explain an individual's clinical reasoning ${ }^{65}$ ('for example, how do osteopaths structure their treatment plan in private practice?').

Early research into clinical reasoning was mainly conducted by the medical profession using quantitative methods, leading to the development of hypothetico-deductive ${ }^{8}$ and pattern recognition $^{48,66}$ methods of diagnostic reasoning. However, other health professions, wanting to gain a deeper understanding of their professional practice began using qualitative research methodolo- gies as a way to explore complex and often discrete aspects of their

discipline, within the context of 'real life' clinical practice. ${ }^{64}$ For example occupational therapists using ethnography, ${ }^{67}$ physiother- apists using grounded theory ${ }^{12,20}$ and nurses using hermeneutics. ${ }^{22}$ These researchers were able to capture more fully the subtle, dynamic and previously hidden aspects of the patientepractitioner

interaction. Observation and/or video-recording of treatment sessions, interviews with practitioners and patients, written materials from the practitioners (for example reflective diaries) have served as data collection methods in research into clinical reasoning all with varying strengths and weaknesses.

The issues and limitations surrounding the methods of acquiring clinical reasoning data are numerous and pose a direct challenge to researchers. Interviewing practitioners is one commonly chosen method, and can be used as a standalone in-depth method, or can occur following the observation of a practitionerepatient encounter (termed 'debriefing') or during a 'live' patient encounter (termed

'think aloud'). ${ }^{68}$ One major limitation of the debriefing/interview 
method is the possibility of subjects to (intentionally or uninten- tionally) reflect on their thinking, thus providing a 'rehearsed' or altered verbal report in accordance with what they think the researcher might like to hear. ${ }^{69}$ Conducting the debriefing immediately after the observation, and the researcher carefully reassuring the practitioner that there are no right or wrong answers, aim to lessen this limitation. ${ }^{68}$

Observation of the patient encounter, either directly in person or indirectly via the use of video recording, is a valuable tool in clinical reasoning research, producing 'rich' data on specific aspects of practice. However, the awareness of a research participant under study poses problems for using observation as a method of col- lecting data. A practitioner (or patient!) conscious of being observed may behave in a way that they may not do normally,

thereby confounding the collected data. This 'reactive' or 'guinea pig' effect ${ }^{70}$ will be present to some degree in all research utilising overt observation methods, but recently the novel use of a headmounted camera has been used to minimise the effect. ${ }^{71}$

\section{Summary}

Clinical reasoning must and does occur within every health profession To understand more about the basis of this clinical reasoning can only help to strengthen the profession's position within healthcare practice. Currently little is known about clinical reasoning processes within osteopathy, and other professions are gaining momentum in this area of theoretical underpinning for their health profession related work. Once clinical reasoning models are established for osteopathy this will help to describe the profession in terms of the competing areas of practice. Throughout the history of osteopathy, numerous theories and models of prac- tice have been proposed and taught. However in light of contem- porary research into clinical reasoning the role that these models and underlying principles play in clinical reasoning, is yet to be investigated. In view of a growing number of osteopaths and a healthcare landscape that demands a reflective and evidence- informed approach to practice, an exploration of these issues is timely and necessary for the further development of osteopathy as a profession. Developing an understanding of clinical reasoning from an osteopathic perspective will enable existing practitioners to refer to a body of research, and thereby facilitate them to reason more effectively. The osteopathic profession should build on the progress made by many other health professions. Research is needed to address some of the issues discussed in this article, and thereby help to illuminate the clinical reasoning of the osteopath.

\section{Acknowledgements}

Thanks to the British Naturopathic and Osteopath Association and the Osteopathic Educational Foundation for their support of Oliver Thomson's Doctoral research. Thank you to Dr lan Drysdale for his helpful comments.

\section{References}

1. General Osteopathc Council. Surveys and statistics. Available from, http://www. osteopathy.org.uk/resources/surveys-statistics/; 2010.

2. National Institute for Health and Clinical Excellence. Low back pain: early management of persistent non-specific low back pain (Clinical guideline 88). Available from, http://www.nice.org.uk/cg88; 2009.

3. General Osteopathic Council. Survey and statistics. Available from, http://www. osteopathy.org.uk/uploads/survey2snapshot_survery_results_2001.pdf; 2001.

4. The Department of Health. Quality agenda. The Government's Expenditure Plan 2000-2001: departmental report. Available from, http://webarchive.national archives.gov.uk; 2000

5. Jones M, Edwards I, Gifford L. Conceptual models for implementing biopsy- chosocial theory in clinical practice. Man Ther 2002;7:2e9.

6. Jones MA. Clinical reasoning in manual therapy. Phys Ther 1992;72:875e84.
7. Borrell-Carrio F, Suchman AL, Epstein RM. The biopsychosocial model 25 Years later: principles, practice, and scientific Inquiry. Ann Fam Med 2004;2:576e82.

8. Elstein AS, Shulman LS, Sprafka SA. Medical problem solving: an analysis of clinical reasoning. Cambridge, Mass.; London: Harvard University Press; 1978.

9. Edwards I. Unpublished paper cited by Jones M: clinical reasoning and pain. Man Ther 1995; 1

10. Edwards I. Clinical reasoning in three different fields of physiotherapy. A qualitative case study approach. University of South Australia, Adelaide 2001;Vols. I and II. Unpublished PhD Dissertation

11. Fleming $\mathrm{MH}$. Clinical reasoning in medicine compared with clinical reasoning in occupational therapy. Am J Occup Ther 1991a;45:988e96.

12. Jensen GM, Gwyer J, Shepard KF. Expert practice in physical therapy. Phys Ther 2000;80:44e52, 28-43; discussion.

13. Benner PE. From novice to expert: excellence and power in clinical nursing practice. Menlo Park, Calif.: Addison-Wesley Pub. Co., Nursing Division; 1984.

14. Higgs J, Jones MA. Clinical reasoning in the health professions. In: Higgs J, Jones M, editors. Clinical reasoning in the health professions. 2nd ed. Oxford: ButterworthHeinemann; 2000. p. 3e14.

15. Higgs J, Jones $M$, Edwards I, Beeston S. Clinical reasoning and practice knowledge. In: Higgs J, Richardson B, Dahlgren MA, editors. Developing practice knowledge for health professionals. Edinburgh: Butterworth Heinemann; 2004. p. 181e99.

16. Higgs J, Jones MA. Clinical reasoning: an introduction. In: Higgs J, Jones M, editors. Clinical reasoning in the health professions. 2nd ed. Oxford: Butter- worth-Heinemann; 2000. xiv, $322 \mathrm{pp}$.

17. Mattingly C. What is clinical reasoning? Am J Occup Ther 1991b;45:979e86.

18. Mattingly C. The narrative nature of clinical reasoning. Am J Occup Ther 1991a;45:998e1005.

19. Fleming $\mathrm{MH}$. The therapist with the three-track mind. Am J Occup Ther 1991b;45:1007e14

20. Edwards I, Jones M, Carr J, Braunack-Mayer A, Jensen GM. Clinical reasoning strategies in physical therapy. Phys Ther 2004a;84:312e30.

21. Edwards I, Jones M, Higgs J, Trede F, Jensen $\mathrm{G}$. What is collaborative reasoning? Adv Physiother 2004b;6:70e83.

22. Benner $P$, Tanner $C$, Chesla $C$. From beginner to expert: gaining a differentiated clinical world in critical care nursing. ANS Adv Nurs Sci 1992;14:13e28.

23. Payton OD. Clinical reasoning process in physical therapy. Phys Ther 1985;65:924e8.

24. Rogers JC, Holm MB. Occupational therapy diagnostic reasoning: a component of clinical reasoning. Am J Occup Ther 1991;45:1045e53.

25. Tanner CA, Padrick KP, Westfall UE, Putzier DJ. Diagnostic reasoning strategies of nurses and nursing students. Nurse Res 1987;36:358e65.

26. Doody C, McAteer M. Clinical reasoning of expert and novice physiotherapists in an outpatient orthopaedic setting. Physiotherapy 2002;88:258e68.

27. Unsworth CA. The clinical reasoning of novice and expert occupational ther-apists. Scand I Occup Ther 2001;8:163e73.

28. Benner PA, Tanner CA, Chesla CA. Expertise in nursing practice: caring, clinical judgement and ethics. New York: Springer Pub. Co; 1996.

29. Mattingly C, Fleming $\mathrm{MH}$. Clinical reasoning: forms of inquiry in a therapeutic practice. Philadelphia: F.A. Davis; 1994

30. Jensen GM, Gwyer JM, Hack LM, Shepard KF. Expertise in physical therapy practice. Boston, Mass: Oxford: Butterworth-Heinemann; 1999b.

31. Sluijs EM. Patient education in physiotherapy: towards a planned approach. Physiotherapy 1991;77:503e8.

32. Fisher A, Fonteyn M. An exploration of an innovative methodological approach for examining nurses' heuristic use in clinical practice. Sch Inq Nurs Pract 1995;9:277e9. 263-76; discussion.

33. Schell B, Cervero R. Clinical reasoning in occupational therapy: an integrative review. $A m$ J Occup Ther 1993:47:605.

34. Unsworth CA. Clinical reasoning: how do pragmatic reasoning, worldview and client-centredness fit? Br J Occup Ther 2004;67:10e9.

35. Goethals S, Gastmans C, de Casterle BD. Nurses' ethical reasoning and behav- iour: a literature review. Int I Nurs Stud 2010;47:635e50.

36. Gordon M, Murphy CP, Candee D, Hiltunen E. Clinical judgment: an integrated model. ANS Adv Nurs Sci 1994;16:55e70.

37. Beeston S, Simons H. Physiotherapy practice: practitioners' perspectives. Physiother Theory Pract 1996;12:231e42.

38. Edwards I, Delany C. Ethical reasoning. In: Higgs J, Jones M, Loftus S, Christensen N, editors. Clinical reasoning in the health professions. 3rd ed. Oxford: Elsevier ButterworthHeinemann; 2008. xiii, $504 \mathrm{pp}$.

39. Higgs J. Clinical reasoning in the health professions. 3rd ed. Oxford: Elsevier Butterworth-Heinemann; 2008.

40. Jones $M$, Jensen $G$, Edwards. Clinical reasoning in physiotherapy. In: Higgs J, Jones $M$ Loftus $\mathrm{S}$, Christensen N, editors. Clinical reasoning in the health professions. 3rd ed. Oxford: Elsevier Butterworth-Heinemann; 2008. xiii, 504 pp.

41. Jones MA, Rivett DA. Introduction to clinical reasoning. In: Jones MA, Rivett DA, editors. Clinical reasoning for manual therapists. Edinburgh ; New York: But- terworth Heinemann; 2004. xiv, $445 \mathrm{pp}$.

42. Embrey DG, Guthrie MR, White OR, Dietz J. Clinical decision making by experienced and inexperienced pediatric physical therapists for children with Diplegic Cerebral Palsy. Phys Ther 1996;76:20e33.

43. Jensen GM, Shepard KF, Gwyer J, Hack LM. Attribute dimensions that distin- guish master and novice physical therapy clinicians in orthopedic settings. Phys Ther 1992;72:711e22. 
44. Jensen GM, Shepard KF, Hack LM. The novice versus the experienced clinician: insights into the work of the physical therapist. Phys Ther 1990;70:314e23.

45. Resnik L, Jensen GM. Using clinical outcomes to explore the theory of expert practice in physical therapy. Phys Ther 2003;83:1090e106.

46. Swanson HL. Influence of metacognitive knowledge and aptitude on problem solving. $J$ Educ Psychol 1990;82:306e14.

47. Terry W, Higgs J. Educational programmes to develop clinical reasoning skills. Aust J Physiother 1993;37:47e51.

48. Groen GJ, Patel VL. Medical problem-solving: some questionable assumptions. Med Educ 1985;19:95e100.

49. Barrows HS, Feltovich PJ. The clinical reasoning process. Med Educ 1987;21:86e91.

50. Smith AE. Osteopathic diagnosis: history taking. Br Osteopathic J 1971;5:10e5.

51. Smith AE. Osteopathic diagnosis. Br Osteopathic J 1971b;5:2e8.

52. Esteves E. J. Clinical reasoning in osteopathy: a Comparative study of experi- enced and Advanced beginner Practitioners. Oxford Brookes Univ 2004; Unpublished thesis in partial fulfilment of the master of Arts in education

53. Sprafka SA. Clinical problem solving. In: Ward R, editor. Foundations for osteopathic medicine. 2nd ed. Philadelphia: Lippincott Williams \& Wilkins; 2003. p. 257e79.

54. Richardson B, Higgs J, Dahlgren MA. Recognisng practice epistemology in the health professions. In: Higgs J, Richardson B, Dahlgren MA, editors. Developing practice knowledge for health professionals. Edinburgh: Butterworth Heine- mann; 2004. p. $1 \mathrm{e} 14$.

55. Sackett DL, Rosenberg WM, Gray JA, Haynes RB, Richardson WS. Evidence based medicine: what it is and what it isn't. BMJ 1996;312:71e2.

56. Portney LG. Evidence-based practice and clinical decision making: it's not just the research course anymore. J Phys Ther Educ 2004;18:46e51.

57. Higgs J, Titchen A. Towards professional artistry and creativity in practice. In: Higgs J, Titchen A, editors. Professional practice in health, education and the creative arts. Oxford: Blackwell Science; 2001. p. 273e90.

58. GOsC. General Osteopathic Council. Standard 2000. Framework and standard. London: GOsC; 2000
59. Higgs J, Titchen A. Rethinking the practice-knowledge Interface in an Uncertain world: a model for practice development. Br J Occup Ther 2001;64:526e33.

60. Still AT. Osteopathy: research \& practice. Kirksville; 1910.

61. Special Committee on Osteopathic Principles and Osteopathic Technique by Kirksville College of Osteopathy and Surgery. The osteopathic concept. An interpretation. J Osteopathy 1953;60:7e10.

62. Rogers F, D'Alonzo Jr G, Glover J, Korr I, Osborn G, Patterson M, et al. Proposed tenets of osteopathic medicine and principles for patient care. J Am Osteopath Assoc 2002;102:63e5.

63. Still AT. Philosophy of osteopathy. Kirksville; 1899.

64. Arocha JF, Patel VL. Methods in the study of clinical reasoning. In: Higgs J, Jones M, Loftus $\mathrm{S}$, Christensen N, editors. Clinical reasoning in the health professions. 3rd ed. Oxford: Elsevier Butterworth-Heinemann; 2008. xiii, 504 p.

65. Loftus S, Smith M. A history of clinical reasoning research. In: Higgs J, Jones M, Loftus S, Christensen N, editors. Clinical reasoning in the health professions. 3rd ed. Oxford: Elsevier Butterworth-Heinemann; 2008. xiii, 504 p.

66. Patel VL, Groen GJ, Arocha JF. Medical expertise as a function of task difficulty. Mem Cognit 1990;18:394e406.

67. Gillette NP, Mattingly C. Clinical reasoning in occupational therapy. Am J Occup Ther 1987;41:399e400.

68. Unsworth C. Review of methodologies for researching clinical reasoning. In: Schell $\mathrm{BAB}$, Schell JW, editors. Clinical and professional reasoning in occupational therapy. Philadelphia, Pa.; London: Lippincott Williams \& Wilkins; 2008. p. 371e400.

69. Fowler LP. Clinical reasoning strategies used during care planning. Clin Nurs Res 1997;6:349e61.

70. Webb E, Campbell D, Schwartz R, Sechrest L. Unobtrusive measures: nonreactive research in the social sciences; 1966. Chicago.

71. Unsworth CA. Using a head-mounted video camera to explore current conceptualizations of clinical reasoning in occupational therapy. AJOT: Am J Occup Ther 2005;59:31. 